\title{
Taking part: Engaging knowledge on health in clinical encounters
}

\author{
João Arriscado Nunes, Patrícia Ferreira*, Filipa Queirós \\ Center for Social Studies, University of Coimbra, Colégio de S. Jerónimo, Apartado 3087, 3000-995 Coimbra, Portugal
}

\section{A R T I C L E I N F O}

Article history:

Available online $\mathrm{xxx}$

\section{Keywords:}

Participation

Knowledge

Information

Health care

Asthma

Experience

\begin{abstract}
A B S T R A C T
Clinical encounters are the most widely shared form of engagement of citizens with health care and medical knowledge and a major setting for the constitution of the health-aware, somatic citizen and are included in the repertoire of participation in the field of health. Following Joelle Zask's notion of participation, we propose to look at clinical encounters as an instances of "taking part" in the field of health through the mutual engagement of diverse forms of knowledge and experience. Through interviews with health professionals and patients diagnosed with asthma, we explore clinical encounters as settings where physicians and patients mutually engage in a process of contesting, sharing and appropriating medical knowledge and information, while recognizing the normative authority of medical knowledge and expertise and the status of biomedicine as a form of veridiction. Clinical encounters are described as processes where citizens qua patients appropriate biomedical knowledge and health information for coping with health problems and the disruptions they generate in their lives, even if their outcomes are uncertain concerning the binding power of medical authority. Patients' engagements with health care services and health professionals and their use of biomedical knowledge for the (self) management of their condition offers a privileged entry point into a neglected dimension of citizen participation in the field of health.
\end{abstract}

๑) 2014 Elsevier Ltd. All rights reserved.

\section{Introduction}

Patient participation has been prioritized in international policy initiatives since the World Health Organization declaration of Alma-Ata in 1978 (WHO, 1978), in research programmes and also as part of the health professional (WHO, 1978; Collins et al., 2007). "Knowledge, skills and motivation of individuals" are tools for patients to exercise their rights and responsibility and to participate in their health care. According to Mavis (2014), it is necessary for patients to "manage one's own health care" by participating in their medical encounters." While it may be relatively easy to prescribe or advocate participation (whether in a research project, in a policy document, or in a clinic), it is less easy to understand how it works, or how to make it happen (Collins et al., 2007).

Participation in health evokes the involvement of citizens - as patients, users of health care or consumers - in the planning and management of health care systems and organizations, in the design, monitoring and assessment of research and clinical trials or in social movements and associations (Epstein, 1996, 2007; Dodier,

\footnotetext{
* Corresponding author.

E-mail addresses: jan@ces.uc.pt (J.A. Nunes), pat.ferreira@gmail.com, patriciaferreira@ces.uc.pt (P. Ferreira), anaqueiros@ces.uc.pt (F. Queirós).
}

2003; Callon et al., 2011; Brown and Zavestoski, 2005; Akrich et al., 2008; Lima et al., 2005; Biehl, 2007). Recent contributions to research have attended to different forms of engagement of citizens with the practices and forms of knowledge involved in health care and in interventions in public health and health promotion legitimated by (bio)medical knowledge (Rose, 2007; Briggs and MantiniBriggs, 2003). These include the most common kind of encounter between citizens, health care practices and medical knowledge, the clinical encounter, as the main site of exposure to biomedical knowledge and health information for most users of health care services. From the 1980s on, landmark ethnographic and conversation-analytical studies on the topic were published (Heath, 1986; Silverman, 1988; Atkinson, 1981; Collins et al., 2007). These focused initially on clinical encounters as episodes of interaction between physicians and patients; later contributions examined how diseases and subject positions are enacted in and through these episodes of interaction (Atkinson, 1995; Berg and Mol, 1998; Mol, 2002).

A strong case can be made for a convergence between studies of clinical encounters and the broader theme of participation in health. Those studies may help shed light on how participatory subjects are constituted in the field of health and how the specific entanglements of knowledge, norms and subjectivity, shaped through clinical encounters and reconfigured as part of both 
patients' and clinicians' experiences, allow further exploration of the diverse responses of citizens to the injunction to "participate". Whereas participation in the health domain is most often understood as the involvement of citizens in the management or governance of health institutions or in the debate and deliberation on health policies within different kinds of fora, clinical encounters may be approached as a form of "taking part", of mutual, noncompulsory engagement of health professionals and patients in the enactment of health care (Zask, 2011), in which participation consists of three aspects: to take part, to contribute a part, to receive a part. These appear as privileged venues for an inquiry into how the normative authority of medicine is faced with the difficulties of translating into binding conceptions of health and disease and compliance with medical advice.

Studies on participation studies often highlight the status/power differential between health professionals and patients as well as the divergences between lay and medical knowledges and experiences (Protheroe, 2013). The capacity and legitimacy to produce knowledge on health certified as "true" is commonly regarded as a prerogative of biomedicine and of the institutions and agents authorized to produce and disseminate it. This knowledge is presumably transferred to patients and health care users, who are expected, first, to act, at most, as informants on their deficits or misunderstandings regarding health, and, secondly, to contribute their willingness to become subjects of health literacy and to draw on the knowledge transferred to them to act on their habits and behaviour, in order to comply with prescriptions for a healthy life and for taking responsibility for the care of oneself.

If we regard these encounters, instead, as providing the occasions for a joint, ongoing construction of both definitions of what the problems are and how to respond to them, and of what counts as relevant knowledge for that purpose, the roles assigned to clinician and patient are destabilized. Each party draws on a repertoire of experiential and cognitive resources associated with their respective life experiences. Since what is brought into the encounter by the parties is neither an inflexible, authoritative set of statements which are part of a discourse of veridiction (Foucault, 2012), nor a blank sheet or a set of false beliefs to be eradicated or corrected, but complex configurations of experience and knowledge. The encounter itself becomes an ongoing process of confrontation and exchange of these experiences and forms of knowledge, and its possible - though uncertain - outcome may be a reconfiguration of the repertoires of the parties, which, in turn, may affect their engagements with other participants in future encounters. Clinical encounters may thus provide a venue for the joint participation of physicians and patients in the reconfiguration of extant relations between scientific/expert and experience-based forms of knowledge within the health domain. This paper attempts to redescribe these encounters as instances of taking part in occasions for both clinicians and patients to decenter conceptions of knowledge and information on health, from deficit or remediation models and asymmetrical transfers to a more flexible and contingent play of diverse experiences and knowledges and their reconfiguration through mutual engagement. In other words, can clinical encounters elicit neglected dimensions of participation as "taking part", through the entanglements between knowledge, norms and subjectivity that take place during the constitution of the relations in these encounters?

The work reported on here is based on research with patients diagnosed with a chronic respiratory disease, conducted as part of the project "Evaluating the state of public knowledge on health and health information in Portugal". The project intended to design and enact a strategy and tools for assessing the knowledge on health of the Portuguese population, focussing on a set of conditions defined as priorities by the Portuguese Ministry of Health's National Health
Program and selected as priorities for the production of health information materials within the Harvard Medical School - Portugal Program - a joint venture for research on translational science and health information - and how these materials are received and appropriated by specific publics. The proposed study design focused on three conditions for which health information materials were developed by Program grantees, namely cancer (breast and colo-rectal), asthma and child obesity. We shall deal here with asthma, focussing on the experience of patients' engagements with health services and health professionals and in accessing, assessing and using information on health, namely that imparted through clinical encounters, since participation is also promoted as an important aspect of self-management in chronic illness (Protheroe, 2013).

\section{Empirical work}

We collected and analysed patients' narratives of experience with asthma, complemented by interviews with physicians and parents of children diagnosed with that condition. A schedule for intensive, semi-structured interviewing was designed through an adaptation of the McGill Illness Narrative Interview (MINI) (Groleau et al., 2006). MINI is an interview schedule which is divided into a common core of modules aimed at eliciting narratives of the experience of the subject in relation to a specific condition including an open module which allows the respondent to offer an account of her experience drawing on her own vocabulary and expressive resources. Other modules allow a more focused and detailed exploration of how the respondent makes sense of the condition, her experience of engaging with health care services and professionals and other forms of therapy, how the condition affected her life and how she related to information (Groleau et al., 2006). The adapted schedule was complemented with guidelines for interviewing.

The research focused on a) how subjects made sense of the condition of interest through explanatory models or salient prototypes (Groleau et al., 2006) and whether, under what circumstances and how subjects search for, access, appropriate, interpret and, eventually, share and act on medical information related to the condition; b) how these two aspects are related to specific trajectories/processes associated with the experience of illness and with encounters with health care services and professionals.

Subjects were selected through, sampling for range (Small, 2009) which allows a deliberate selection of cases for maximizing the range of differences in experiences/trajectories, regardless of how frequent these may be. The rationale behind this procedure is that unusual or "rare" situations or experiences provide insights into the processes of interest which would go unnoticed when searching for commonalities or for the most frequent occurrences of the phenomenon of interest. The procedure is case-based and process-tracing-oriented - i.e., its basic analytical units are cases, corresponding to the illness experience narratives of subjects, which provide the materials for the exploration of the processes of interest. Process-tracing was achieved through coding each interview and identifying categories associated with these processes through the comparison of the coded interviews. The criteria for closure of analysis were theoretical saturation. This set of procedures was based on the grounded theory approach (Bryant and Charmaz, 2010; Charmaz, 2006).

Although patients provided the bulk of the interviews, we interviewed as well parents of children diagnosed with asthma and health professionals. The presence of parents is central to children's attempts to cope with the disease as a conspicuous presence in their daily life. As for physicians, we used here two interviews, with a specialist in chronic respiratory diseases at a Paediatric Hospital, 
and with a specialist in family medicine at a Health Centre. These semi-structured interviews aimed at reconstructing the health information and communication chains allowing people to "make their own health" through encounters between their experiencebased knowledge of disease, health and the body, and health institutions and professionals and biomedical knowledge.

Our main data set included 40 interviews with patients diagnosed with asthma conducted at Hospital São João in Porto and at the Paediatric Hospital of Coimbra. Interviews were on average 45 min long, and were tape recorded with the subjects' permission. Notes were taken by the interviewer to keep track of the topics covered in both the open-ended and thematic parts of the interview.

Fieldwork started after approval by the ethics committees of the two hospitals. Clinicians identified the patients to be interviewed, described the study and asked them if they accepted to participate (all patients who were invited accepted). Patients were interviewed after giving informed consent. Interviews were transcribed and coded. Interviews were selected with the purpose of providing stories which allowed us to present cases that stood out during the research project for their display of the complexity of the clinical encounter as participation.

Subjects were encouraged to talk about their experiences with asthma and health information throughout their life course. We identified and characterized in detail: (i) what counts as health knowledge for patients; (ii) their different ways of describing and explaining disease; (iii) diverse experiences of living with the condition and of engaging with health care services and health professionals; (iv) different modes of managing the disease; and (v) access to sources of information, the assessment of their credibility, their appropriation and use. Narrative analysis allowed an exploration of the entangled relations between subjects, biomedical knowledge, health care practices, health communication chains and mediations related to how information is received and appropriated.

Each subject was encouraged to tell her story drawing on vocabularies and narrative styles she was familiar with, and to identify the topics she regarded as relevant to her story. . This made possible a broader exploration of the subject's shaping of notions like health, illness or suffering, information and knowledge and of the venues of experience wherein they emerged, beyond those explicitly associated with health care, such as health centers or hospitals. It was clear in all of the interviews, however, that the specific settings where the interviews were conducted with patients - hospital wards - and the process of recruitment of subjects entailed awareness of the limits and purpose of the interview, which prevented dispersion. The second part of the interview explored a number of topics in a more structured way, referring back, when needed, to the initial, open-ended narrative.

\section{Discussion}

The term "clinical encounter" describes any interaction between a patient and a practitioner aimed at the diagnosis, evaluation or treatment of the patient's condition. It is an ongoing process with well-defined roles (doctor and patient), enacted in different ways and with different outcomes depending on the way doctor and patient interactively negotiate the authority and binding force of medical knowledge and expertise. The accounts of these encounters by both doctors and patients/users of health care often suggest different readings of what is at stake in them and how their outcomes are understood. Medical information and its appropriation and use figure prominently in these accounts. Patients' stories provide entry points into the ways "health" is understood in relation to life experiences, and descriptions of what patients regard as a condition of "normality" which they aim to restore when they fall ill (Canguilhem, 1966).

Normality is often acknowledged in the breach, and does not necessarily correspond to medical definitions of health or normality. Some events associated with trauma or disease - such as some forms of acute disease, or an accident - may be regarded as highly disruptive of the patient's life, whereas others may become part of a reconfiguration of normality - as is the case of chronic conditions, especially those involving some form of self management. When questioned about the best way of dealing with asthma, Mariana states:

“... in my case what was important was explaining to me what I should ... I should be careful with prevention ... I should take the inhaler every twelve hours and that would reduce to a minimum the number of crises. And in fact ... it did reduce them. But I think the most important thing is to explain the causes, how it can be controlled, or not ... explain, in fact, what for each person causes an asthma crisis, so that people know what they should avoid or they should seek to control as much as possible."

Mariana, 31 years old

The normative constraints associated with the recognition of a breach in normality in the terms of biomedical knowledge may lead to a dismissal or marginalization of both the descriptions and the concerns of the patient, based on her experience, as irrelevant or secondary to effective medical intervention, but it may also face the doctor with the limits set by those normative constraints on the understanding of the experience of illness and distress (Biehl, 2007).

The return to normality is a central feature of a significant number of the narratives we have collected. Frank (1997) describes them as "restitution narratives". They allow people to assimilate their condition into their worldviews and routines, and to adapt to it the best way possible, in a socio-cultural context marked by the values of independence and autonomy. This response to the condition converges partly with the framing, by health care professionals, of asthma as a chronic disease susceptible of selfmanagement by the patient herself. In the case of one patient, who is also a nursing student, diagnosed with asthma as an adult, her narrative recalls how she related to biomedical knowledge drawing on her memories of the moment she was diagnosed:

"I found it strange that she (the doctor) did not clarify the whole thing, that she did not enlighten me. There are people who do not want to know and they are entitled to not wanting to know, but from the moment I showed interest I think she should have been more enlightening than she actually was."

Beatriz, 21 y. o.

\section{And later, on an appointment with her family doctor:}

"I have had some connection, for some time, with my family doctor, she is a person I trust whom I told what happened and she found it odd; but she always had a very positive reaction and thought that that stuff was somewhat beyond her area of competence and that she did not have the skills to work with my case, I think she had the best attitude, which was: acknowledging some limitation she might have, she gave me directions for continuing the prescribed therapy, since it was being effective, and suggested that I wait for the appointment (at the health centre) and that I should go there if some change happened."

Beatriz, 21 y.o. 
After that, Beatriz was followed by allergology specialists at the hospital, where she was finally diagnosed with asthma:

"Somehow, I was already expecting it, as I said, the medication that was prescribed, all the situations that were popping up, I was expecting it (...), but I was not counting on it to be so sudden, hearing that word, it was a shock, at the time. It took me some days to somehow digest the situation and understand the implications it would have for my life, which at the time I thought would be greater than they actually were, which are practically none, for the time being, since the situation is under control, the symptoms are controlled and since then I never experienced another, similar episode."

Beatriz, 21 y. o.

In this case, the patient's engagement with biomedicine involved, first, "a shock" associated with hearing the very word describing her condition (despite her expectation of that diagnosis). Later on, however, it allowed her to take control over a part of her life which she feared would be disrupting. Recognizing the symptoms and controlling them, allowing her to restore some degree of normality to her life is associated, in this case, with learning how to recognize symptoms and use medication as part of the resources she can draw on to prevent and, eventually, respond to episodes which appear as disruptions of the sense of normality she is seeking to restore and protect.

Parents seek as well ways of managing their children's asthma, looking for medical knowledge and information they can share outside the clinical encounter, at their children's school, for instance. A doctor describes physical education as a major concern of parents with children with asthma, and he acknowledges his role as not only a provider of information and advice on asthma, but also as being sensitive to the specific situations in which that role is to be enacted and, in particular, how to negotiate a role for other actors so that they can act as enforcers of medical authority in matters of health:

"The approach is generally made through an information sheet, in this case, written by me. I hand it to the parents, the sheet is addressed to the teacher in charge of the class and to the physical education teacher. I recommend that when handing that letter parents have as well a conversation with the physical education teacher, and that the conversation be cordial and not a medical requirement, because it is badly received when it is imposed by the doctor. The letter includes recommendations for physical education, what we think the teacher should do as that student is concerned (...) And then there are factors inherent to ... the doctorteacher relationship. The physical education teacher has been trained and, so, thinks that he will know what to do and won't need any recommendation, many see it that way."

João, MD

The assertion of medical authority depends on the capacity of the doctor, to translate authoritative information into advice whose effectiveness will depend on how it is channelled along the different sources and agents of authority involved in the situation (doctor, teacher, parents). This example offers a striking instance of how, as Biehl and Moran-Thomas (2009) state, human relations with biomedical technologies (including the "soft" technologies of health information and health literacy) are being progressively built outside the clinical context and are invading the social contexts of people's lives, becoming part of "the very fabric of symptoms and identities".

Schools are one kind of privileged setting for this distributed assertion of medical authority. But, as the following passage suggests, this process is far from linear. The presence of competing authorities - of teachers and parents - generates friction and tensions which have to be handled by the doctor and remind him of the need to acknowledge that making the normative authority of medicine binding is an exercise fraught with uncertainty, and requires a capacity to engage with a local web of forms of power and authority. This doctor describes physical education as a major concern of parents with children with asthma and as one of those loci where different forms of experience, knowledge and authority meet and may potentially clash.

Those in charge of producing and circulating medical information often treat accounts of patients' experiences as evidence of a deficit in knowledge on health or of false beliefs in need of correction. Patients are mostly regarded as informants, rather than co-producers of knowledge and of information or partners in the design of interventions in health literacy and health promotion. This vision still seems to pervade the description, by a senior general practitioner working at a primary health care unit in Coimbra of his management of information for patients:

"The first question I ask the individual who also suffers from asthma is what he knows about asthma and, following what he tells me, I try to explain what it is ... or improve the information he volunteered, which sometimes is the most basic thing, and then do a bit of explanation of how medication works and for what purpose. And only three or four messages are passed. Little by little, we will construct more information."

Carlos, MD

While discussing the production of pamphlets for the "lay" public on health issues, this doctor dwells on the difficulties of passing on a specific message through the use of that type of medium:

"My PhD thesis has demonstrated that, in fact, a leaflet is the best way of passing on information, as long as the information it contains is duly validated and produced according to good practices and good norms. How sentences are constructed, the number of sentences ... (...) I can show you, as an example, something I did a few years ago, from the work for a study which was published (he hands out a small piece of paper with some topics on hypertension). This is about hypertension: what it is and, on this side, how medication acts (...). This is what works best for users ... (...). It was my initiative, all that was validated. What the objectives were which I intended to get across, what statements would allow these objectives to get across. Then it was passed along a number of nurses, doctors, psychologists, sociologists, public. And health journalists, too, to put together short sentences. Then it was applied to a set of people to find out whether they understood it, if it was easy to read, how long it took them to read it, and, finally, a linguist checked whether all the sentences were well constructed. Then we started the field phase, which consisted of picking up a set of individuals and, on the basis of random selection, hand the information to some of them and not to others. We then sought to understand how, over a period of nine months, how the degree of control evolved and the total risk of the individual among those who had received the leaflet and those who had not. We found out 
that there had been a statistically significant improvement among those who had received it."

Carlos, MD

A similar approach is described by a paediatrician:

“(...) the paediatrician always engages with the antecedents, with schooling, and tries to relate to the child. Considering now my individual, particular case, I very much value literacy, Portuguese, speaking correctly, writing correctly, I value a lot, and I use every moment with children for that, and with adolescents too. The way I often get their attention is by explaining them the etymology of a word, of those medical terms they are afraid of, you know? If I put a name on them, here is an example, you are allergic to a domestic dust accarus named dermatophagoid, this scares anyone, you know? Illustrative and explanatory, I want to explain what grass are, I get an image, I've got some books there, too, before the internet I had books which I showed to parents. I want to show them the pollen calendar; I have the calendar and show it. I show websites which are informative, namely those containing images."

João, MD

Patients are assumed, here, to be ignorant on medical matters, but also as having the capacity to understand medical terms and concepts, as long as these are translated into vernacular language, using a vocabulary they are familiar with, and drawing as well on images, which are assumed to stand in a relation of immediacy and transparency to those who look at them, allegedly absent from written and spoken language, which require translation. If there is any contribution to the design of information items, materials and messages, that contribution is requested "downstream" of the creation of those materials and messages, as ways of checking whether these get across to basically ignorant, uninformed or misinformed subjects.

According to Daniela, a patient, doctors are a primary and reliable enough source of information on asthma, and she considers that the information they give her is sufficient. Latter, when we asked her if she ever had the curiosity or initiative of looking for information on asthma in other sources, she answers:

"No, it's like I told you, I learned everything by living."

Daniela, 30 years old

Another patient, when asked about the sources of information he regarded as most credible, replied.

"This doctor (reference to the doctor currently attending him), this is now my second appointment ... she now prescribed me a few more things and I do believe it. I... I find it positive, and, as I say, if I get better, I obviously will have to say that she is a good professional."

Eduardo, 84 y. o.

In contrast, when Mariana was asked about whether she felt the need to confront the information given by an expert with other information, her reply was:

"Yes. In this case, because I thought it was too much or ... I mean ... I found it strange. I had never met anyone who had asthma and who had three inhalers. And then I thought 'maybe ... let me confirm whether this is normal, if it's not normal or if there's an alternative", and then ..."

Mariana, 31 y.o.

Beyond the differences in their compliance with medical advice and prescriptions, what these interviews have in common is that they draw on the health care system and health professionals as their main sources of information and knowledge on health, something which has been repeatedly confirmed by successive surveys. However, the engagement of patients with health professionals and health care services and their experience of living with illness and managing it according to what is recognized by professionals as appropriate standards do not mean that they will necessarily appropriate or endorse biomedical explanations of disease.

The clinical trajectory of Daniela would seem to confirm deficitbased descriptions of patient knowledge. After a period in which she ignored the disease, an episode occurred which was to be a turning point in her relation to asthma, taking her to the hospital:

“... So I started with Ventilan once, twice, three, four, five, six, seven, eight, nine, ten times and so on ... (...) I don't remember precisely what the limit was, but it shouldn't be used like that. The fact is that that was the way I used Ventilan, so if it didn't work the first time I used it again. I had always done it, only that time, perhaps because I was exposed to too many allergens at the same time, the crisis was more serious ... (...) Then I had to be admitted to the hospital because I almost had a cardiac arrest due to excessive medication, because I let the crisis evolve too much ..."

Daniela, 30 y.o.

Daniela's case points to the unpredictability of what patients will do with the information they access. The sources of that unpredictability may lie where doctors would not usually look for them. In going back over this episode, Daniela recognizes that she was aware that hers was not the right way to administer the medication she was prescribed. But she added that that was how she managed crises when they appeared, and it worked. Later in the interview, she admitted that the failure to follow the prescribed course of treatment was due to economic problems, since she couldn't afford the prescribed inhaler, different from the one she actually used.

Concerns with the kind of information an asthma patient should get from health care professionals appear to be constant, even when having family members with the same condition might seem to be of help in learning how to cope with the disease. Most patients are willing to control their disease, to take steps to prevent crises, or to learn what to do when a crisis starts, and thus, at least ideally, they are prepared to embed the management of the disease within their habits and routines. For some, knowing "their asthma" is a critical aspect of this management:

"- And the information they gave you on the first visit, was it enough to know your disease better?

- Yes it was. And you know why? I immediately started to adapt to it and try to put away suffering. I started thinking "this is it, I will follow this treatment, I will get used to it, to feeling it", and when the crises start, I detect them right away. It's still far away but I know I'm going to be sick, and that's for sure."

Amélia, 56 y.o. 
At this level, another cluster of heterogeneous profiles may be found, as different people adopt different strategies and ways of managing asthma. Even though most of the patients have access to medical information through practitioners, learning how to deal with their asthma draws on the plastic or porous boundaries between the medical knowledge that is communicated and the knowledge already held by the individual. This individual knowledge might be informed by his/her experience(s), others' experiences understood as prototypes, knowledge shared within a community or among patients themselves, etc. How medical information is taken up and added to the existing repertoires of knowledge varies considerably, and makes any assessment of what health communication specialists describe as the effectiveness of health information difficult to characterize and assess, especially when the degree of compliance with medical advice is at stake. This much is recognized by doctors themselves. Carlos describes the complexity of managing the expectations of the patients in clinical encounters regarding the use of medical treatments:

"Most patients bring with them signs or symptoms and they want us to interpret what is there, and that is the drama of the question, because from then on people want to be treated for what we found and not for what they felt."

Carlos, MD

From the point of view of this doctor, diagnosing is more than the answer to a research question; it is about the "agenda of the patient" and the unpredictability of medical diagnosis should be a good reason to be responsive to that agenda:

"That is why I insist with my interns and with myself that we get to understand the agenda of the problems of the patient in order to succeed in our attempts to respond to it, and not just to respond to our research question, which is, how to get to a name for a diagnosis."

Carlos, MD

According to this physician, patients expect doctors to provide them with a diagnostic and appropriate medical treatment in order to solve a problem they regard as being within the purview of medicine. Based on his experience, what brings the patient to a medical appointment is an event which interferes with her life and a sense of change in her life which disrupts its predictable course; but it also provides an encounter with discursive, diagnostic and therapeutic resources in an environment where the patient tries to recover normality resorting to the biomedical apparatus.

To the question "What is the value of the experience of the patient at a medical appointment following from respiratory problems?" the doctor's answer was:

“(...) They show me signs and symptoms, they want me to interpret them and come up with a solution. But then they want me to give them the solution to what I found and not to what they've got. And they think that the receipt includes medication to improve their health, not to respond to the problems they brought with them."

Carlos, MD

During the clinical encounter, the doctor listens to the patient's story - a process in which the patient is reflecting and reconstructing his own experience through the knowledge and practices that define his way of living, while the health professional attempts to make sense of the subject's accounts and respond to her request for help. Both of them know that the way the story is told and the attention given to it has important consequences for the patient's access to health care, therapeutics or medication (Gwyn, 2001).

One of the major concerns of Carlos is that the clinical encounter may become the place where people look for medication as a response not only to their diseases, but also to medicalize conditions people should learn to deal with in other ways. This also shapes the ongoing relation between doctor and patient during the clinical encounter:

"People look forward to the immediate consumption of a health good which, for them, may appear as salvation or as a means of improving their quality of life. And they forget about the rest (...) It's much easier for them to say:' just give me the medication, so that I have some relief, because the rest is much more complicated."

Carlos, MD

The accounts of some patients suggest that they may be looking for responses beyond the drug-centred therapies of allopathic medicine. This may take them into searching for more "natural" ways of managing their condition, without discarding chronic medication:

"I am, in part, against chronic medication, when they make sense it's alright, but when they don't I think they are not necessary, I tried to replace them with something more natural, more physiological, and what I found was sea water, a physiological serum.."

Beatriz, 21 y.o.

Doctors themselves may express concerns not only with what they regard as the misuse of medication, but also with the seemingly irresistible trend towards an increase in the medicalization of different kinds of troubles, responding to the expectations and hopes of the patients fuelled by the increase in promissory notes associated with the alleged availability of techniques and drugs to deliver personalized care (Nunes, 2012):

"And then they invent a couple of other tests to try to find one more problem and, thus, they force people to look for whether they "have this", they create fear, doctors are forced to unnecessarily increase their costs and try to unnecessarily prescribe medication."

Carlos, MD

Interview data suggest that during clinical encounters the knowledge regarded as most relevant by both parts is the one that allows the patient to manage health and illness through the diagnostic and therapeutic resources available to biomedicine. In this sense, medical knowledge is acknowledged by both parts as a form of veridiction in Foucault's sense (2012), a form of true knowledge on health which, as such, should bind both parts to practices regarded as its appropriate enactment. But this does not necessarily mean that there is a convergence between the respective understandings of what the problems are, what biomedical interventions may achieve and how they are appropriated by patients within ongoing reconfigurations of their experiences of what counts as normality and as illness. In other words, the recognition by both parts of the normative authority of medicine does not necessarily translate into normative force (Rouse, 2002), understood as compliance by patients with interventions and actions prescribed under the authority of the doctor or of medical information imparted by sources acknowledged as legitimate and reliable. 
What counts as knowledge and as information is vulnerable to contestation by the contributions of the experience-based knowledge of patients to the diverse ways of relating to health, disease and health care. This provides an opening into the problematic assumption that the recognition by "lay" subjects of the authority of medical knowledge and information corresponds to a willingness of those subjects to be transformed into "literate" subjects, consenting to be bound by the normative force of biomedical knowledge:

\section{“- And how do you see your role as a doctor, meaning, a privileged provider of health information to patients?}

- That is my big problem. As, in quotation marks, an opinion maker, how what I am saying is interpreted by whoever I am transmitting it to (...) we often say here a few things which are not duly interpreted. That's why, in the end, as you say, a positive behavioural cognitive attitude consists in trying to ask: 'So, doubts? Have you understood it? Tell me what I told you', and sometimes they don't tell me anything of what I said."

Carlos, MD

The doctor embraces his role as an agent of knowledge transfer, but he also realizes that literacy is not only about transferring information:

"The adult learns what he is interested in learning at the time he is interested in learning, depending on his local willingness, the moment and the best way of making and impression on him."

What emerges from patient's narratives is a diversity of modes of articulating descriptions and explanations of the disease, of its symptoms, causes, aetiology and management and of the experience of living with the condition. One would look in vain for the presence, beneath that diversity, of a subject bound to a common adherence to the biomedical description of the condition New possibilities seem to emerge, thus, for engaging with knowledge production on health in ways which enhance the relevance and visibility of patient experience and knowledge, and this much is acknowledged by some professionals:

\section{"-What kind of knowledge production do you think is more rele- vant? Or what contexts makes more sense to think medical infor- mation for?}

- Point one: what is relevant for the patient. Point number two: what is very important for society. Point number three: what is acceptable by people. Point number four: what is in some way consensual for providers and receivers of care."

Carlos, MD

While keeping his commitment to medical knowledge as form of veridiction, this physician appears to be resisting the linear logic of deficit models of information and, thus, open up opportunities for patients to configure their uses of literacy in ways that engage their situated experiences (Carter, 2008). Materials from patient narratives suggest that the implementation of models of literacy aimed at encouraging patients to changes in behaviour reinforces the power of biomedicine to expand its influence on increasing domains of social life, but does not necessarily have the binding effects expected by its designers and promoters. Accounts of the ongoing, intersecting life experiences constituting subjects provide an empirical ground for an exploration of engagement with health care services and health professionals which takes seriously the capacities and achievements of "lay" citizens to generate their own configurations of knowledge and to participate in the health domain, both through communication with professionals and interventions in the planning of health care or of health promotion initiatives (Groleau, 2011). Disregarding the importance of the meaning and experience of illness and of the related search, by patients, for the return to normality, the social and cultural contexts within which people use and make sense of medical knowledge become invisible. This may not always be apparent, especially when the sharing of information and knowledge, beyond being a personal choice of the patient, is regarded as part of the doctor's job:

"Maybe the doctor, somehow, did not have enough data to give me an accurate diagnosis, and I do understand that, but I think she should have given me more information than the one she gave me at the time."

Beatriz, 21 y.o.

These statements are of considerable relevance if one keeps in mind that the health professional is regarded by patients as the main source of health information, and in particular of the information needed for the effective self management of asthma:

“- What do you think a patient should know on the day or at the appointment where he is told that he has asthma? What do you think is important for a patient to know? What do you think the doctor should tell the patient?

- To communicate as he did, yes? To tell the patient about things which may negatively affect (the management of) the disease, yes? So that we can avoid them. Taking your medication, yes? Try appropriate medication, because sometimes it doesn't, medication does not always work at first, yes?"

Sofia, 39 y.o.

Even if the sharing of information by doctors is highly valued, this still does not answer the question of what patients do with that information, how they process it and how they use it for acting on their condition. Some accounts provide considerable detail on that matter. But an adequate understanding of whether and how medical information and advice become a binding force in patients' lives requires an ethnographic inquiry into the venues of experience where medical knowledge is deployed and contributes to the shaping of subjects and of their relation to the authority of medicine as a form of veridiction (Foucault, 2012).

\section{Conclusions}

Studies of participatory procedures and fora involving both scientists/experts and "lay" members of publics have documented how the agendas of scientists and experts tend to set the terms of their engagements and thus reiterate the epistemic authority of scientific/technical knowledge (Carvalho and Nunes, 2013). This is particularly clear where these procedures include a preliminary process of "educating" the citizens who participate in identifying and becoming familiar with what is regarded by experts as the "right" agenda for debate. Encounters of health professionals and users of health care services are certainly vulnerable to a reassertion of the normative authority of medicine and public health along those lines and to attempts at translating these into binding 
prescriptions for action. A closer look at the dynamics of these encounters, however, even when they are framed by reference to allegedly true knowledge, good practices and good norms, opens up spaces allowing the reconfiguration, through mutually accountable statements and practices, even within the narrow limits permitted by the framing, of the repertoires of experience and knowledge of those involved in the encounter.

Participation, if it is to be more than a token involvement in public relations, is conditional on such a process of reconfiguration in settings where how health and knowledge on health is defined is not settled in advance, but becomes a playing ground for divergent conceptions which may be at odds with those consistent with certified, biomedical knowledge. According to Zask,

Participation understood as "taking part" implies both individuals permeable to the innovative quality of experiences and activities which are deepened or enriched by the diversity or points of view, practices and involvements which generate them (Zask, 2011: 48).

Can encounters with (bio)medicine like the ones discussed in this paper afford the conditions for participation thus understood? Or are they irremediably bound, despite the room for manoeuvre displayed by patients' accounts and by the reflections of some physicians, to reiterate their conventional roles? How does the often unchallenged binding force of biomedicine, of its knowledge, practices and institutions contribute to the shaping of citizen participation? What kinds of exclusions - of topics, modes of knowledge, vocabularies, forms of expression, entities and actors are enacted in relation with that binding force? Is there room for the response-ability (Barad, 2007) of patients and users within encounters framed by the normative authority of medicine and aimed at the binding commitments of participants to statements and practices associated with apparently solid examples of "good practices" and "good norms"? In other words, can these encounters be refashioned as "taking part"?

\section{Acknowledgements}

Work for this paper was part of the project "Evaluating the state of public knowledge on health and health information in Portugal", funded by the Portuguese Science and Technology Foundation within the Harvard Medical School - Portugal Program (HMSPIISE/SAU-ICT/0003/2009/FCOMP-01-0124-FEDER-013012). The authors wish to thank the collaboration of the two research groups based at the Center for Social Studies of the University of Coimbra (Liliana Sousa, Marta Roriz and Carlos Barradas) and at the Institute for Molecular and Cell Biology (Liliana Abreu, Álvaro Mendes, Júlio Santos and Maria Rui).

\section{References}

Akrich, M., et al. (Eds.), 2008. The Dynamics of Patient Organizations in Europe. Presses de l'École des Mines, Paris.
Atkinson, P., 1981. Clinical Experience: the Construction and Reconstruction of Medical Reality. Gower Publishing, London.

Atkinson, P., 1995. Medical Talk and Medical Work. SAGE, Thousand Oaks, CA

Barad, K., 2007. Meeting the Universe Halfway. Duke University Press, Durham, NC. Berg, M., Mol, A. (Eds.), 1998. Differences in Medicine: Unravelling Practices, Techniques, and Bodies. Duke University Press, Durham, NC.

Biehl, J., 2007. Will to Live: AIDS Therapies and the Politics of Survival. Princeton University Press, Princeton, NJ.

Biehl, J., Moran-Thomas, A., 2009. Symptom: subjectivities, social ills, technologies. Annu. Rev. Anthropol. 38 (1), 267-288.

Briggs, C., Mantini-Briggs, C., 2003. Stories in the Time of Cholera: Racial Profiling During a Medical Nightmare. University of California Press, Berkeley.

Brown, P., Zavestoski, S. (Eds.), 2005. Social Movements in Health. Blackwell Publishing, Oxford.

Bryant, A., Charmaz, K., 2010. The SAGE Handbook of Grounded Theory. SAGE Thousand Oaks, CA.

Callon, M., et al., 2011. Acting in an Uncertain World. MIT Press, Cambridge, MA

Canguilhem, G., 1966. Le normal et le pathologique. P.U.F, Paris.

Carter, S., 2008. How Literacy Lives: Rhetorical Dexterity and Basic Writing Instruction. State University of New York Press, Albany, NY.

Carvalho, A., Nunes, J.A., 2013. Technology, methodology and intervention: performing nanoethics in Portugal. Nanoethics 7 (1).

Charmaz, K., 2006. Constructing Grounded Theory: a Practical Guide Through Qualitative Analysis. SAGE, Thousand Oaks, CA.

Collins, S., et al. (Eds.), 2007. Patient Participation in Health Care Consultations. Open University Press, Maidenhead.

Dodier, N., 2003. Les leçons politiques de l'épidémie de sida. Editions de l'EHESS, Paris.

Epstein, S., 1996. Impure Science: AIDS, Activism, and the Politics of Knowledge University of California Press, Berkeley.

Epstein, S., 2007. Inclusion: the Politics of Difference in Medical Research. University of Chicago Press, Chicago.

Foucault, M., 2012. Mal faire, dire vrai. Fonction de l'aveuen justice. University of Chicago Press/Presses Universitaires de Louvain, Chicago/Louvain La Neuve.

Frank, A.W., 1997. The Wounded Storyteller: Body, Illness, and Ethics. University of Chicago Press, Chicago,

Groleau, D., Young, A., Kirmayer, LJ., 2006. The McGill Illness Narrative Interview (MINI): an interview schedule to elicit meanings and modes of reasoning related to illness experience. Transcult. Psychiatry 43 (4), 671-691.

Groleau, D., 2011. Embodying "health citizenship" in health knowledge to fight health inequalities, Rev. Bras, Enferm. 64 (5), 811-816.

Gwyn, R., 2001. Communicating Health and Illness. SAGE Publications, London.

Heath, C., 1986. Body Movement and Speech in Medical Interaction. Cambridge University Press, Cambridge.

Lima, N.T., et al. (Eds.), 2005. Saúde e Democracia: História e Perspectivas do SUS Editora Fiocruz/PAHO/WHO, Rio de Janeiro.

Mavis, B., 2014. Patient participation in clinical encounters: a systematic review to identify self-report measures. Health Expect. http://dx.doi.org/10.1111/ hex.12186 [Epub ahead of print].

Mol, A., 2002. The Body Multiple: Ontology in Medical Practice. Duke University Press, Durham, NC.

Nunes, J.A., 2012. Embodied expectations: the somatic subject and the changing political economy of life and health. In: Caldas, J.C., Neves, V. (Eds.), Facts, Values and Objectivity in Economics. Routledge, London, pp. 126-137.

Protheroe, J., 2013. 'Permission to participate?' A qualitative study of participation in patients from differing socio-economic backgrounds. J. Health Psychol. 18 (8), 1046-1055. http://dx.doi.org/10.1177/1359105312459876.

Rose, N., 2007. The Politics of Life Itself: Biomedicine, Power, and Subjectivity in the Twenty-first Century. Princeton University Press, Princeton, NJ.

Rouse, J., 2002. How Scientific Practices Matter: Reclaiming Philosophical Naturalism. University of Chicago Press, Chicago.

Silverman, D., 1988. Communication and Medical Practice: Social Relations in the Clinic. SAGE, Newbury Park, CA.

Small, M., 2009. 'How many cases do I need?' On science and the logic of caseselection in field-based research. Ethnography 10 (1), 5-38.

World Health Organization, September 1978. Primary Health Care: Declaration of Alma-Ata International Conference on Primary Health Care. USSR, Alma-Ata. Available at: http://www.who.int/publications/almaata_declaration_en.pdf? ua=1 (accessed 30.06.14.).

Zask, J., 2011. Participer: Essai sur les formes démocratiques de la participation. Éditions Le Bord de l'Eau, Lormont. 